\author{
ENRIQUE CAMACHO CÁRDENAS \\ UNIVERSIDAD DE SEVILLA
}

\title{
El proceso constructivo del Sagrario Metropolitano de Guadalajara: la llegada de José Gutiérrez y el inicio de la arquitectura neoclásica en la ciudad
}

AS APORTACIONES DOCUMENTALES sobre la construcción del sagrario tapatío proporcionadas en el estudio de Juan Bautista Iguíniz fueron clave para entender el retraso del inicio de la obra y el dilatado proceso constructivo del edificio. El autor enumeró las causas que obligaron a paralizar los trabajos de construcción en varias ocasiones, estableciendo los momentos de la construcción y la labor de los arquitectos que intervinieron en el inmueble. ${ }^{\mathrm{I}}$ Los escasos estudios monográficos acerca del edificio y los de carácter general han venido reiterando las cuestiones mencionadas sin profundizar en su contenido y sin ampliar las razones que determinaron el retraso de las obras. ${ }^{2}$

I. Juan Bautista Iguíniz, "El Sagrario Metropolitano de Guadalajara. Reseña histórica", Memorias de la Academia Mexicana de la Historia, t. I, núm. I, México, enero-marzo de 1942.

2. Véanse sobre el tema de estudio, Margarita del Carmen Noguera Miceli, "La arquitectura neoclásica religiosa en la Guadalajara del siglo XIx", tesis de maestría, Guadalajara, Universidad de Guadalajara-Centro Universitario de Arte, Arquitectura y Diseño, 2000; Alfonso Moya Pérez, "El Sagrario Metropolitano de Guadalajara", en Arquitectura religiosa en Jalisco. Cinco ensayos, Guadalajara, Amate, I998, pp. I3 I-I62; Javier Huízar Zuno, "El neoclásico”, en Ramón Mata Torres, Iglesias y edificios antiguos de Guadalajara, Guadalajara, Ayuntamiento de Guadalajara/Cámara de Comercio, I979, pp. 373-378. 
A pesar de que estos estudios dan una serie de motivos económicos y políticos que impidieron que la obra se realizara en menos tiempo, se ignoraron otras cuestiones, entre ellas las derivadas de la llegada a la ciudad de otro arquitecto procedente de México. El nombramiento del académico José Mariano Domínguez y Mendoza como director de la obra supuso un intento por continuar la construcción, aunque al final no intervino en el edificio, poniendo en relieve la precaria situación económica por la que atravesaba la Iglesia. Por otro lado, la llegada de José Gutiérrez a la ciudad para llevar a cabo la obra del hospicio Cabañas y la apertura de una escuela pública para la enseńanza de diversas disciplinas, tales como dibujo y arquitectura, significó la incorporación del neoclásico a las tierras novogalaicas. Para ello fue decisiva la figura del obispo Juan Cruz Ruiz de Cabañas, si bien otras personalidades participaron en este hecho. Con la ampliación de datos sobre el origen y desarrollo de la obra arquitectónica, el acercamiento a las causas que llevaron a José Gutiérrez a la ciudad y su intervención en el templo, así como las noticias referentes a la presencia en Guadalajara del arquitecto académico Domínguez y Mendoza, se pretende una aproximación más sólida a la historia de la construcción del edificio, permitiendo así una visión coherente de lo que supuso su fábrica.

El sagrario fue la primera parroquia de la ciudad hasta finales del siglo XVIII, cuando el obispo Antonio Alcalde y Barriga en 1782 decidió crear dos parroquias más, la de Mexicaltzingo al sur y la del Santuario de Guadalupe al norte. No recibió el rango de metropolitano hasta I863, con la erección de la diócesis de Guadalajara en arzobispado. Desde que se decidió dotar al sagrario de un templo propio hasta que se concluyó su fábrica, pasó más de un siglo. La donación que realizó el obispo Alcalde y Barriga para llevar a cabo la obra y que en ese momento no se pudo utilizar, la falta de arquitectos en la ciudad que pudieran afrontar una empresa arquitectónica bajo las nuevas ideas del neoclásico, los problemas políticos que se desencadenaron a principios del siglo XIX con motivo de la guerra de la Independencia de México, así como los escasos recursos económicos de la Iglesia, fueron los factores que determinaron el retraso en el inicio de la obra y el dilatado proceso constructivo del inmueble.

Hasta iniciarse su fábrica, tuvo desde el siglo xvi diversos emplazamientos, pero nunca un edificio propio. En un principio dispuso de una capilla en la primitiva iglesia que sirvió de catedral hasta que se realizó el actual templo catedralicio. En 1618, cuando tuvo lugar la dedicación de la catedral nueva, se trasladó a otra capilla situada en el cubo de la torre norte del inmueble. En la misma época en que se consagró la catedral en I7I6, se llevaron a cabo diver- 
sas obras en dicha capilla, decorando su interior, construyendo un retablo y dotándola de una sacristía para su servicio. Años después fue necesario buscar otro edificio que asistiera a la parroquia del sagrario para mejorar los servicios ofrecidos a los feligreses. La capilla dedicada a Nuestra Señora del Pilar en el barrio de San Sebastián, cuya construcción se inició en 1720 y concluyó poco tiempo después, sirvió de apoyo para este fin. ${ }^{3}$

El origen del edificio se sitúa en el primer tercio del siglo XviII. El 2 de junio de 1722 se pensó en la necesidad de erigir en la ciudad un edificio exclusivo para el sagrario, por lo que se pidió al tesorero de la catedral que valorara si era conveniente construirlo. Además, se barajó la idea de comunicarlo con el edificio de la catedral, abriendo una puerta en el altar de San Isidro. Es significativo destacar que desde un principio se ideó edificar el templo del sagrario en el lado norte de la catedral, ya que el altar de San Isidro estuvo ubicado en la nave del evangelio hasta I 827 , siendo éste el más próximo a la capilla situada en el cubo de la torre norte. ${ }^{4} \mathrm{El} 20$ de septiembre de 1758 se decidió retener 2000 pesos anuales de la fábrica de la catedral para la construcción del nuevo edificio, proponiendo el obispo Francisco de San Buenaventura Martínez de Tejada y Díez de Velasco que se realizara en el lugar que ocupaba el viejo Colegio Seminario del Señor San José, demoliendo este inmueble y convirtiendo su espacio en una pequeña plaza. El Seminario Conciliar, fundado por el obispo Felipe Galindo y Chávez en I696, se situó frente a la iglesia de Nuestra Señora de la Soledad en el costado norte de la catedral. El edificio se amplió en I735, aunque en 1740, durante el gobierno del obispo Juan Gómez de Parada, se inició una nueva construcción, la que es hoy el Museo Regional de Guadalajara. Se decidió derribar el inmueble antiguo el to de julio de $178 \mathrm{I}$, no para albergar una plazuela que sirviera para llevar a cabo actividades comerciales, como proponía el procurador mayor de Guadalajara, sino

3. Iguíniz, op. cit., pp. 39-45.

4. La ubicación de dicho altar se indica en Luis del Refugio Palacio, La catedral de Guadalajara, Guadalajara, Artes Gráficas, 1948, p. 45.

5. Juan Bautista Iguíniz, Guadalajara a través de los tiempos. Relatos y descripciones de viajeros y escritores desde el siglo XVI hasta nuestros dias, Guadalajara, Banco Refaccionario de Jalisco, I950, t. I, p. 62, n. II; Fernando Martínez Réding, Enciclopedia temática de Jalisco, Guadalajara, Gobierno del Estado de Jalisco, I992, t. IV, p. 23. Además, para la ampliación de datos sobre la construcción del edificio del seminario, véase Jesús Jiménez, "Los edificios del Seminario Tridentino de San José de Guadalajara", en Mata Torres, op. cit., pp. I53-166. 
para quedar en beneficio de la fábrica de la catedral. ${ }^{6}$ De esta forma se mantuvo la idea de considerar la zona norte de la catedral como la más apropiada para edificar el templo. Tras la demolición del seminario se volvió a insistir en la construcción del sagrario, baptisterio y habitación para los curas, y aunque el obispo Alcalde y Barriga donó io ooo pesos para la edificación, no se logró poner en marcha la obra. En I785, con motivo de un desprendimiento en la fábrica de la catedral que dejó inhabilitada el área de la sacristía, el baptisterio y la vivienda de los sacerdotes, se trasladó el sagrario a la capilla de San Javier. Este suceso despertó nuevamente el interés y la urgencia de construir un sagrario. En el cabildo del to de abril de ese año, el prelado Alcalde y Barriga propuso que, para evitar que los gastos de la edificación recayeran sobre los fondos de la fábrica de la catedral y la Real Hacienda, se buscara a alguien que donara el dinero suficiente para su inmediato levantamiento.7 $\mathrm{Al}$ mes siguiente el propio obispo cedió todos los fondos de su renta para la construcción del sagrario, baptisterio y otras oficinas necesarias, una vez demolidas las fabricadas en adobe, por el avanzado estado de ruina que presentaban. La donación alcanzó los 80000 pesos. ${ }^{8}$ El obispo novogalaico estableció una serie de consideraciones en la donación. Por ejemplo, advirtió que la cesión de su patrimonio no le privaría de distribuir y gastar lo necesario en otras necesidades, tales como socorrer a los pobres. También puntualizó que el dinero que se acumulara hasta el día de su fallecimiento perteneciente a su Cuarta Episcopal se invirtiera en la obra, bien para la fábrica o para el adorno y culto del templo. Con esta donación, Alcalde y Barriga quiso tener el control de la obra y de los gastos que se hicieran en ella, estando la dirección bajo su aprobación, así como el nombramiento del arquitecto, el intendente y el mayordomo. Además especificó en qué personas tenía que recaer la dirección de la obra tras su fallecimiento. ${ }^{9}$ A pesar de esto, los trabajos de construcción no se

6. Archivo Histórico del Cabildo Eclesiástico de Guadalajara (en adelante AHCEG), Libro de actas capitulares, núm. I2, ff. 246v-247r.

7. AHCEG, "Expediente formado con motivo de las obras de el sagrario y torres de esta catedral y el nuevo ajuste de su director don Mariano Mendoza", Sección Secretaría, Serie Hacienda, 1830, caja 25, exp. 9, s.f.

8. Iguíniz, "El Sagrario Metropolitano", op. cit., p. 47. El extracto de las donaciones, limosnas y fundaciones que hizo dicho prelado en los 2 I años que estuvo en la diócesis de Nueva Galicia se recoge en Laura Castro Golarte, Noticias del fraile de la calavera. Antonio Alcalde y Barriga en Guadalajara, Guadalajara, México, Cámara Nacional de Comercio de Guadalajara/Instituto Cultural Ignacio Dávila Garibi, 1998, pp. 92-94.

9. AHCEG, "Expediente formado con motivo de la donación del ilustrísimo señor Alcalde 
iniciaron en ese momento, pues la escasez de cereales que atravesaba la ciudad obligó al obispo a entregar parte de su donación para disminuirla. ${ }^{\text {IO }}$

Tras el fallecimiento de Alcalde y Barriga en I792, hubo que esperar unos años hasta que se retomó el asunto de la construcción. Así, la real cédula del 23 de enero de 1804 aprobó la donación de Alcalde y Barriga para llevar a cabo la construcción, concediendo permiso al presidente de la Audiencia de Guadalajara, José Fernando Abascal y Souza, para que interviniera en la obra con el acuerdo del obispo. ${ }^{\text {II }}$ En ella el rey indicó, tanto al nuevo prelado Juan Cruz Ruiz de Cabańas como al presidente de la Audiencia, que las trazas del sagrario las realizara la Real Academia de San Carlos de México. No obstante, el monarca ya había dado licencia para la edificación el io de noviembre de 1785, aunque en aquel momento no tuvo efecto. La omisión del obispo tapatío al comunicar al rey la necesidad de la construcción del sagrario sin mencionar el nombre del donador perjudicó también el inmediato comienzo de las obras. Así, el monarca comentó que Alcalde y Barriga no consideró oportuno revelar este hecho,

persuadido de que solo así quedaba asegurada y tendrá efecto [...] pero que era de esperar que mi soberana real piedad anuente a la intención de dicho vuestro antecesor aprobare la aplicación que éste señaló por ser la más propia de este género de bienes en las circunstancias de la grave necesidad que había de construir y adornar la citada capilla y bautisterio, y que como tal podía recomendárseme, pasándose antes a esa Audiencia dichos autos para la aprobación de lo actuado según se verificó por el de nueve de enero de mil setecientos noventa y tres. $^{\mathrm{I} 2}$

para la construcción del sagrario", 1785, Sección Secretaria, Serie Culto, caja I, exp. I9, s.f. Véase "Apéndice documental", doc. I.

Io. Iguíniz, "El Sagrario Metropolitano...", op. cit., p. 47.

II. La real cédula se presentó, atendiendo a las cartas del presidente de la Audiencia de Guadalajara Jacobo Ugarte y Loyola, del is de septiembre de I795, que no recibió contestación, y la de su sucesor en la presidencia, José Fernando Abascal y Souza, del 5 de noviembre de I802. En ellas se informó sobre los expolios del obispo Alcalde y Barriga, la donación y la necesidad de construir el edificio. AHCEg, Sección Secretaría, Serie Hacienda, caja I3, exp. I5, s.f.

I2. El expediente formado con motivo de las obras del sagrario y las torres de la catedral que se realizó en 1830, en el que se presentan los antecedentes históricos de ambas obras, difiere en la fecha en que se dio la licencia para el levantamiento del edificio. Así, se dice: "Se practicaron las diligencias convenientes para obtener del rey la correspondiente licencia que en efecto concedió como consta de la real orden de io de noviembre de 1795 comunicada por 
El 4 de septiembre de I804, el presidente de la Audiencia de Guadalajara, José Fernando Abascal, remitió al virrey de Nueva España, José de Iturrigaray, el plano del terreno donde se pretendía edificar el templo e insistió en la necesidad de un arquitecto para su levantamiento, debido a la ausencia en Guadalajara de algún maestro capaz de llevarlo a cabo. Abascal consideró indispensable la presencia de un profesor de la Academia de San Carlos que se encargara del proyecto, así como para instruir "en la idea del buen gusto" a los maestros de la ciudad tapatía. El 8 de octubre del mismo año se ordenó la realización de las trazas del edificio a la Academia de San Carlos. ${ }^{13}$

Si bien Antonio Alcalde y Barriga fue quien promovió la necesidad de un edificio para el sagrario, no fue sino hasta el gobierno del obispo Juan Cruz Ruiz de Cabańas cuando se impulsó la construcción, encargando el proyecto al arquitecto José Gutiérrez. El 7 de enero de I805, el obispo Ruiz de Cabańas propuso al cabildo eclesiástico solicitar un maestro en México para que diera lecciones de arquitectura y dibujo en la ciudad tapatía. Antes de esta solicitud, el obispo se había informado sobre quién podía encargarse de este trabajo. Ruiz de Cabañas se comprometió a retribuirle con I ooo pesos anuales, sugiriendo al mismo tiempo al cabildo de la catedral la idea de nombrarlo arquitecto y maestro de las obras de la iglesia catedral. ${ }^{14}$ Días más tarde, el cabildo decidió aceptar la propuesta del obispo con una asignación de 400 pesos anuales sobre el fondo de fábrica de la iglesia. ${ }^{15} \mathrm{El}$ prelado novogalaico informó tanto al Consulado de Guadalajara como al cabildo eclesiástico para que uno y otro cuerpo lo nombraran respectivamente como su maestro de arquitectura. ${ }^{16}$

el marqués de Sonora al señor regente presidente de la Real Audiencia y por éste al cabildo; y en su consecuencia se trató de señalar el sitio, delinear el mapa, y regular los costos, y este encargo se hizo al capitán de ingeniería don Narciso Codina enviado por el virrey para este fin". AHCEG, Sección Secretaría, Serie Hacienda, caja 25, exp. 9, s.f.

I3. Archivo General de la Nación (en adelante AGN), "El señor presidente de Guadalajara sobre que la Real Academia de San Carlos forme el Plano para la obra de la Parroquia de aquella Santa Iglesia y se envíe un facultativo capaz de ejecutarla", Instituciones Coloniales, Indiferente Virreinal, I804-I805, caja 3026, exp. 002, ff. 2r-3v. Véase "Apéndice documental", doc. 2.

I4. AHCEG, "Sobre el nombramiento de Maestro de Arquitectura para las obras que ocurran a la Fábrica de esta Santa Iglesia", Sección Secretaría, Serie Hacienda, I805, caja I3, exp. 26, s.f. Véase "Apéndice documental", doc. 3.

15. Idem. Asimismo, la noticia sobre la solicitud del obispo para que un arquitecto pueda trasladarse a Guadalajara y realizar las obras mencionadas también se recoge con fecha del Is de enero de I805 en AHCEG, Libro de actas capitulares, núm. I5, f. $202 \mathrm{r}$.

I6. AHCEG "Sobre el nombramiento de Maestro de Arquitectura...", doc. cit. 
El I8 de enero, el director de Arquitectura de la Real Academia de San Carlos, Antonio González Velázquez, informó sobre los planos de la obra. Las trazas ejecutadas por José Gutiérrez se componían de planta, fachada y dos secciones. ${ }^{17}$ El precio de los planos fue de 300 pesos. Además, el director de Arquitectura —que puntualizó: "no habiéndolos yo ejecutado respecto a la cortedad de mi vista que es notoria"-, recomendó al arquitecto malagueño como la persona más idónea para llevar a cabo la obra, el cual pedía un sueldo de 2000 pesos anuales por su trabajo. Por aquel tiempo, Gutiérrez, arquitecto académico de mérito, era sustituto de arquitectura en la Academia con un sueldo de 700 pesos anuales, por lo que se solicitó "se sirva elevarlo a la superioridad", a fin de poder conservar su empleo en la Academia pero sin disfrutar de su sueldo, contabilizando su estancia en Guadalajara como tiempo de servicio a la misma e ingresando nuevamente en ella una vez finalizada la obra. ${ }^{18}$

El contrato se celebró en México el 8 de febrero de i 805 . Aunque se le proponía para la construcción del sagrario, el contrato estaba enfocado a la edificación del hospicio que Manuel Tolsá había diseñado y a la apertura de una escuela pública para la enseñanza de aritmética, geometría, arquitectura y dibujo. En él se le exigió que su establecimiento en la ciudad debía durar al menos cuatro años, con el objetivo de poder realizar estos trabajos e impartir durante dos horas diarias lecciones de las disciplinas señaladas. En el último punto del contrato se mencionó que el obispo Ruiz de Cabańas trataría de encomendar a José Gutiérrez la obra del sagrario, cuya planimetría había realizado el propio arquitecto (fig. I). ${ }^{19}$

La llegada de José Gutiérrez a Guadalajara supuso la presencia de la nueva estética académica en la ciudad. El arquitecto nació en Málaga en 1766 e ingresó en la Academia de San Carlos de México en 1787, dedicándose en un principio al ramo de pintura. A partir de 179I se cambió a la disciplina de la arquitectura. Con posterioridad recibió el título de académico de mérito en arquitectura y con ello el reconocimiento de Antonio González Velázquez, director de Arquitectura, y de Miguel Costansó, director de Matemáticas. ${ }^{20}$ Además, gozó de la estima de Manuel Tolsá, quien lo propuso para que

17. No se han localizado los planos originales del edificio en ninguno de los archivos consultados.

I8. AGN, "El señor Presidente de Guadalajara sobre que la Real Academia de San Carlos forme el Plano...", doc. cit., ff. 4r-5v. Véase "Apéndice documental", doc. 2.

19. José López Portillo y Weber et al., El hospicio Cabañas, México, Jus, I97 I, pp. II7-I I9. 20. La doctora Adriana Ruiz Razura ha estudiado la vida y obra de José Gutiérrez, lo que 


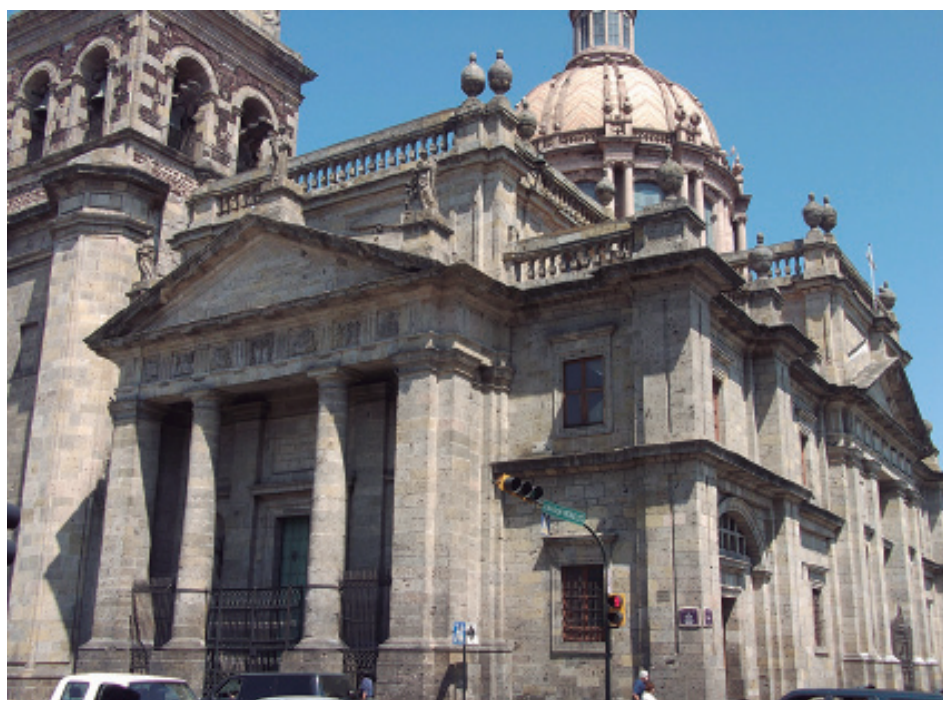

I. Vista general del Sagrario Metropolitano de Guadalajara. Foto: Enrique Camacho Cárdenas, 2010.

llevara a cabo su proyecto de la Casa de la Misericordia en Guadalajara, hoy hospicio Cabańas. Fue director de Arquitectura de la Academia de San Carlos de México desde I8I3 y renunció al cargo en I827 para continuar la labor de director en la Academia de Dibujo de Guadalajara. ${ }^{21}$

Algunos estudios sobre el edificio del hospicio Cabañas han comentado la razón por la que no se contó para esa obra con maestros que estaban desarrollando su actividad arquitectónica en la ciudad tapatía, encargando las trazas del edificio a Manuel Tolsá y construyéndolo José Gutiérrez casi en su totalidad. El maestro Pedro José Ciprés, originario del pueblo de Mezquitán, había construido la torre de la iglesia de San Felipe Neri, gozando su trabajo de un

le permitió aclarar la fecha de nacimiento del arquitecto, basándose en el acta de defunción localizada en el Archivo Parroquial de la Notaría del Sagrario Metropolitano de Guadalajara. Los estudios de carácter general habían señalado, hasta ese momento, el año de 1772 aproximadamente. Adriana Ruiz Razura, "José Gutiérrez, el arquitecto malagueño del neoclásico en Guadalajara, México (I766-1835)", Cuadernos de Estudios del Siglo XVIII, núm. I8, 2008, pp. I8I-2Io.

2I. Elizabeth Fuentes Rojas, La Academia de San Carlos y los constructores del neoclásico. Primer catálogo de dibujo arquitectónico, I779-1843, México, Universidad Nacional Autónoma de México-Escuela Nacional de Artes Plásticas, 2002, pp. 47-49. 
gran reconocimiento. Además realizó un plano de la Alhóndiga de Maíz de Guadalajara en 1793 y otro de la Alhóndiga y Cuartel de Milicias y Carnicería de la ciudad en $1797 .{ }^{22}$ Díaz Morales comentó que no era posible pensar que en la ciudad se ignoraran completamente estos conocimientos técnicos, pues Ciprés, para llevar a cabo la torre de San Felipe Neri, debió tener un dominio de todas las disciplinas que se pretendían impartir en Guadalajara con la apertura de la escuela pública. A pesar de ello, el obispo Ruiz de Cabañas decidió encargar el proyecto del hospicio "al mejor arquitecto de la época". ${ }^{23}$ Es posible, como afirma López Portillo y Weber, que el prelado novogalaico, a su paso por la capital en la que permaneció casi todo I796, pudiera conocer al arquitecto valenciano. Así, una vez establecido en la capital neogallega, el obispo avanzó de manera paulatina en su propósito de erigir un establecimiento de carácter caritativo, siendo hacia I803-I804 cuando se debieron de iniciar las gestiones para la realización de los planos del edificio. ${ }^{24}$ Aunque en esas fechas Ciprés se encontraba en plena actividad, se prefirió para la obra a un arquitecto instruido en las nuevas ideas académicas, siendo a la postre José Gutiérrez quien se encargaría de enseñarlas y difundirlas en territorio novogalaico. No obstante, Ruiz de Cabańas reconoció los méritos profesionales del maestro Ciprés, contando con él para los trabajos preparativos y puentes sobre el río de San Juan de Dios. ${ }^{25}$ Por ello, el deseo del rey en I804 para que realizara las trazas del sagrario la Real Academia de San Carlos, de la misma forma que lo hizo el presidente de la Audiencia de Guadalajara, puso de manifiesto el interés por alejarse de las formas barrocas y extender los postulados de la Academia a otras partes del virreinato (fig. 2).

El 9 de mayo de I805, el obispo neogallego informó al presidente de la Audiencia de Guadalajara que el cabildo eclesiástico había propuesto la cantidad de 400 pesos anuales sobre los fondos de la fábrica de la iglesia para que el arquitecto se hiciera cargo de las obras que se realizaran en la catedral. El consulado de Guadalajara, atendiendo al informe del obispo comentado anteriormente, lo hizo con la cantidad de 600 pesos. La solicitud se aceptó el mes

22. José Antonio Calderón Quijano, Cartografía histórica de la Nueva Galicia, Universidad de Guadalajara (México)/Escuela de Estudios Hispano-Americanos de Sevilla, I984, pp. 76-79.

23. López Portillo y Weber et al., op. cit., p. I I9.

24. El dato se recoge en Alejandro Rosas et al., Hospicio Cabañas, México, Landucci, 200I, p. 89.

25. López Portillo y Weber et al., op. cit., p. II9. 


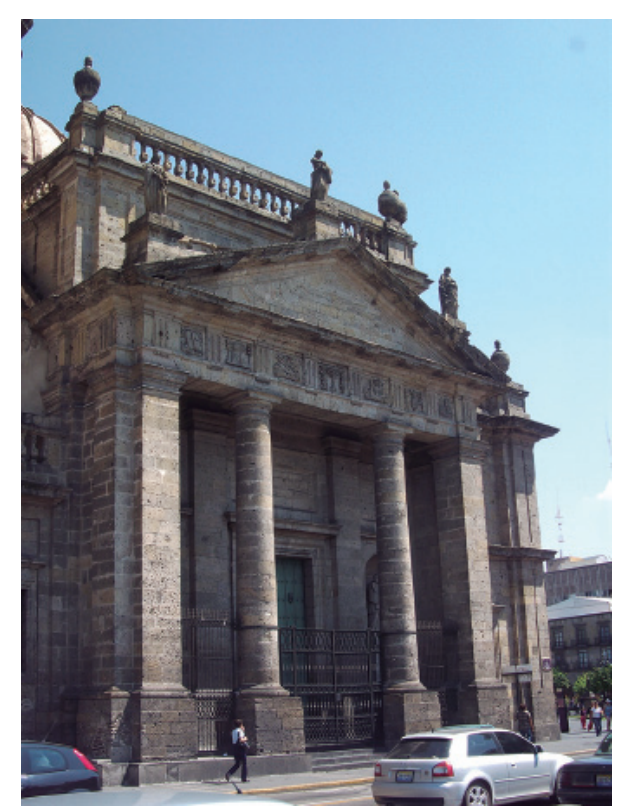

2. Portada principal del Sagrario Metropolitano de Guadalajara. Foto: Enrique Camacho Cárdenas, 2010.

siguiente, dejando al obispo y al cabildo la tarea de establecer las obligaciones del arquitecto. Éstas fueron: el reconocimiento de la fábrica de la iglesia, todos los reparos necesarios y demás obras ordinarias, así como la del sagrario por ser obra extraordinaria y de primer orden. ${ }^{26}$

A pesar de que el establecimiento en Guadalajara del arquitecto José Gutiérrez se produjo en I805, no se tienen noticias de su actividad en el edificio del sagrario hasta 1807 , encargándose durante ese tiempo de las obras del hospicio y la apertura de la escuela pública para la enseñanza de las disciplinas antes señaladas. Aunque en la documentación de i805 se menciona la obra del sagrario como obra "extraordinaria", entendida como prioritaria para diferenciarla de las demás "ordinarias" o secundarias referidas al resto de las obras necesarias en la catedral tapatía, el arquitecto tuvo que encargarse de los trabajos de reparación de las torres del templo, así como de las nuevas trazas para su reconstrucción, durante I806 y I807. Así, el 7 de noviembre de I807 José Gutiérrez calificó de "extraordinaria" la realización de un nuevo plano y la ejecución de las torres, afirmando que la asignación económica con que con-

26. AHCEG, "Sobre el nombramiento de Maestro de Arquitectura"..., doc. cit. 
taba no era suficiente. Por ese motivo, días más tarde, el arquitecto pidió para llevar a cabo estas operaciones I ooo pesos anuales sobre los 400 de los que ya gozaba y 300 más por la realización de los nuevos planos. ${ }^{27}$

En 1807 surgió el debate sobre cuál debía ser el sitio más idóneo para el levantamiento del sagrario, siendo esta discusión uno de los factores por los que se dilató nuevamente el inicio de la construcción. La idea de erigir el edificio en el sector norte de la catedral continuó siendo la opción más apropiada, como lo demuestra la serie de inconvenientes que pronunció el cabildo eclesiástico el 2 de noviembre ante la propuesta de realizar la obra en la zona sur. El cabildo expuso que el lado sur de la catedral, donde se encontraban el atrio y el cementerio, presentaba un espacio reducido que impedía que el edificio gozara de una extensión digna al tenerse en cuenta el continuo crecimiento de la población en Guadalajara. De la misma forma, la nueva construcción modificaba la iluminación que entraba desde ese costado a la catedral, además de eliminar las funciones que tenía el acceso sur a la misma. Éste se utilizaba para el desarrollo de las procesiones del Domingo de Ramos y el Corpus Christi, para descongestionar el edificio catedralicio en los casos de numerosa concurrencia, así como para servir de salida de emergencia cuando temblaba la tierra. La obra, que debía tener una distancia respecto de la catedral de io varas, evidenciaba otros problemas al respecto. Con dicha distancia se creaban unos callejones estrechos entre ambos inmuebles que impedirían el desagüe de las aguas desde los canales de la catedral, provocando humedades en ambas obras. Para evitar eso se tenían que construir conductos subterráneos que dieran solución al sistema de desagüe, aumentando el costo de la obra y sin garantía de que la humedad desapareciera. Al margen de esto, se tuvo en cuenta otra cuestión que podía tener graves consecuencias en la población. En el lado sur se situaba el cementerio, por lo que los trabajos de excavación para cimentar la obra podían ocasionar enfermedades como la peste entre los habitantes.

La situación era distinta en el área norte del templo catedralicio, que contaba con la amplia plaza de La Soledad en la que no se presentaba ninguna de las incidencias comentadas. El cabildo eclesiástico insistió en que en la zona norte, al ser espaciosa, se podría construir "habitación cómoda para los ministros que no consista en una sola pieza como la que designa el mapa, ni sirva como esta de tránsito para el baptisterio: y finalmente las piezas de la secreta-

27. Idem. 
ría, contaduría y tribunal de hacienda no quedarán oscurecidas". ${ }^{28}$ Todas estas opiniones se tuvieron en cuenta, pues el 24 de noviembre se pidió al cabildo que José Gutiérrez señalara en la plaza de La Soledad el terreno que ocuparía el sagrario en caso de construirse finalmente en la zona norte. ${ }^{29}$ No obstante, las razones que expresó el cabildo eclesiástico no tuvieron efecto, ya que el 6 de abril de I8o8, según el oficio del presidente, gobernador e intendente de Guadalajara del día anterior, se acordó que la obra se llevara a cabo en la zona sur, siguiendo las exposiciones sobre el tema que hicieron el fiscal civil, el asesor y José Gutiérrez. ${ }^{30}$ Por fin, el acto de colocación de la primera piedra de la obra tuvo lugar el in de abril de dicho año. ${ }^{31}$

Sin tener conocimiento de las razones que dieron el fiscal, el asesor y el arquitecto, es de interés destacar la decisión final para erigir el sagrario a los pies del templo catedralicio, en el lado de la epístola. Quizá la idea del arquitecto prevaleció no tanto por cuestiones de carácter práctico, técnico o arquitectónico, sino por otras de tipo espacial previamente establecidas. Es de suponer que en I804, cuando se envió el plano del terreno donde se debía realizar la obra, éste no representara una zona concreta, sino toda la referente al entorno de la catedral. De esa forma y teniendo en cuenta que la documentación consultada no hace ninguna referencia al sitio específico donde debía construirse, el arquitecto pudo elegir la zona sur y realizar las trazas del edificio en consideración a las características de dicho lugar, pues sólo se pidió a la Academia que "ejecute el dibujo con la correspondiente elevación y cortes de perfiles que convengan para la mejor inteligencia de la obra". ${ }^{2}$ Por otra parte, tal vez la decisión de José Gutiérrez tuvo muy presente la ubicación del sagrario de la Catedral de México, situado en el lado de la epístola del inmueble. Si bien desde el punto de vista arquitectónico el sagrario de México siguió la tipología de planta de cruz griega utilizada en el de la catedral de Granada,

28. AHCEG, Libro de actas de reuniones de "Pelicano", I773-I880, ff. I3r-v.

29. AHCEG, Libro de actas capitulares, núm. I5, f. 257r.

30. Ibidem, ff. $268 \mathrm{r}$-v.

3I. Sobre este acto véanse José Ignacio Dávila Garibi, Apuntes para la historia de la Iglesia en Guadalajara, México, Cultura, I967, vol. IV, pp. I86-I88; D. Juan Cruz Ruiz de Cabañasy Crespo: biografía de un gran prelado, $7^{\mathrm{a}}$ ed., México, Jus, 1984, pp. 217-219; Refugio Palacio, op. cit., pp. I07-I09; Moya Pérez, "El Sagrario Metropolitano...”, op. cit., pp. I40-I42; Iguíniz, "El Sagrario Metropolitano...", op. cit., pp. 48-49.

32. AGN, "El señor Presidente de Guadalajara sobre que la Real Academia de San Carlos forme el Plano...", doc. cit., f. 2 r. 
así como el interior del mismo repitió el sistema de soportes de la Catedral de México, fue su exterior el que presentó la novedad. La solución adoptada a través de las portadas-retablo y el uso del estípite tuvo una repercusión rápida en las edificaciones posteriores del virreinato. Aunque estas características arquitectónicas no aparecieron en la construcción del templo de Guadalajara, sí se podría pensar en la posible influencia que dicha obra ejerció en José Gutiérrez a la hora de seleccionar el lugar de la construcción..$^{33}$ Lorenzo Rodríguez, en el proyecto del Sagrario Metropolitano de México, siguió no sólo el tipo de planta del modelo que Hurtado Izquierdo realizó para el sagrario de la catedral de Granada, sino también su ubicación, al situarlo a los pies del templo en el lado de la epístola. ${ }^{44}$ Gutiérrez pudo hacer lo mismo en el caso de Guadalajara, ignorando de esa forma todas las incidencias e inconvenientes que presentó el cabildo eclesiástico sobre el sector sur, más problemático y menos espacioso que el norte (fig. 3).

Los trabajos de la obra se desarrollaron con normalidad hasta el inicio de la guerra de la Independencia en I8 10.35 A raíz de este acontecimiento y durante los II años que se prolongó la guerra se suspendieron las labores de construcción. José Gutiérrez regresó a México, donde se le encomendó la dirección de la Sección de Arquitectura de la Academia de San Carlos. En dos años de actividad constructiva, los muros de la obra alcanzaron cinco metros de altura. Hubo que esperar hasta I 835 para reanudar los trabajos, ya que después de

33. El edificio se concibió bajo la tipología de planta de cruz latina, siendo ésta, según el estudio de Katzman, el tipo de planta más usada en los templos del siglo xix en México. Israel Katzman, Arquitectura religiosa en México (I780-1830), México, Universidad Nacional Autónoma de México/Fondo de Cultura Económica, 2002, p. 2 I.

34. La relación entre el sagrario de la catedral de Granada y el de México se puntualizó en Diego Angulo Íníguez et al., Historia del arte hispanoamericano, Barcelona, Salvat, 1950, vol. II, pp. 559-562; Enrique Marco Dorta, "Arte en América y Filipinas", en Ars Hispaniae, vol. XXI, Barcelona, Plus-Ultra, 1973, p. I54. Aunque las obras del sagrario de Granada fueron iniciadas por Francisco Hurtado Izquierdo, maestro mayor de la catedral de Córdoba en ese momento, realizando sus diseños con rapidez, sus continuas ausencias de la ciudad obligaron al cabildo a contratar un nuevo arquitecto en I7I7, José de Bada y Navajas, a quien corresponden el alzado, la decoración y el diseño exterior. Rafael López Guzmán y María Luisa Hernández Ríos (coords.) Guía artística de Granada y su provincia, Sevilla, Fundación José Manuel Lara, 2006, vol. I, p. 48.

35. El 3I de marzo de i8 Io el cabildo eclesiástico mencionó que el dinero perteneciente a los expolios del obispo Antonio Alcalde y Barriga para la construcción de la obra era de 96000 pesos, además de los 8 ooo del caudal destinados a dicha obra que se prestaron al rey. AHCEG, Libro de actas capitulares, núm. I6, f. I2v. 


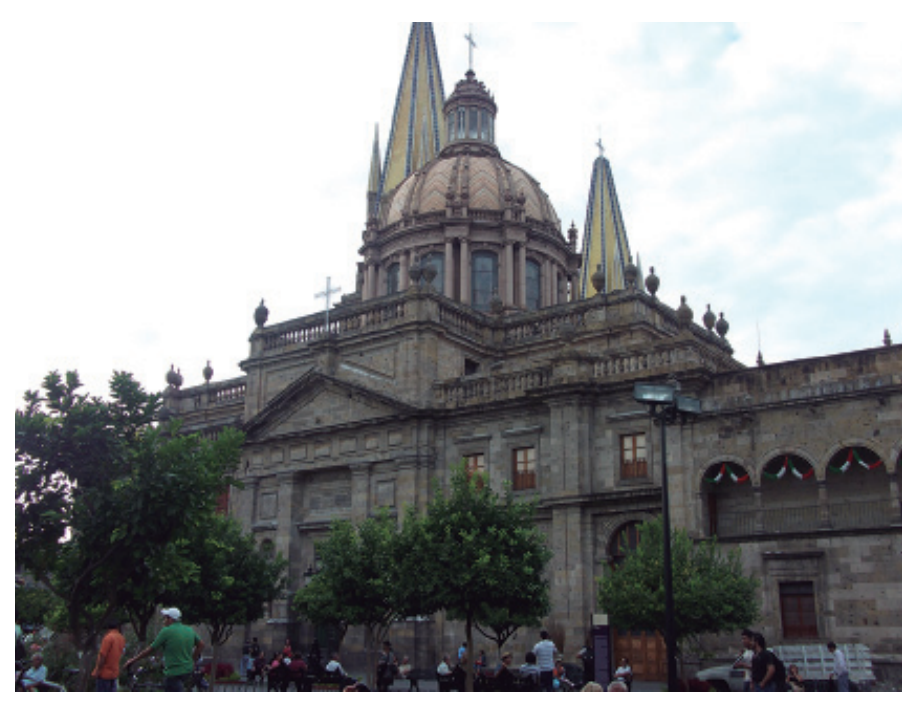

3. Fachada lateral del Sagrario Metropolitano de Guadalajara.

Foto: Enrique Camacho Cárdenas, 2010.

la guerra la Iglesia se había quedado sin recursos económicos para continuar con dicha empresa arquitectónica. ${ }^{36}$ No obstante, los trámites para reiniciar las obras del sagrario comenzaron con anterioridad con la presencia de un nuevo arquitecto, desarrollándose de forma paralela a las obras de reparación que se llevaron a cabo en la catedral. El I3 de febrero de I829, el cabildo eclesiástico nombró al arquitecto académico José Mariano Domínguez de Mendoza para trabajar en las labores constuctivas del recinto catedralicio. Asociado con José Gutiérrez, director de la obra de la iglesia catedral, procedió a acelerar los trabajos de cerramiento que se estaban realizando. El año siguiente y antes de concluir estas labores, el arquitecto comunicó al comisionado de la obra, Diego Aranda, la incertidumbre sobre su contrato. Así, el 23 de junio de I830 Aranda trasladó su reclamación al cabildo eclesiástico, exponiendo que después de finalizar la obra encomendada para ese año, el arquitecto no sabía si tenía que continuar con las correspondientes a las torres de la catedral y la del sagrario. De ese modo, solicitó al cabildo que le informara anticipadamente sobre este asunto, bien para llevar a cabo los trámites pertinentes sobre su nuevo contrato o, por el contrario, para gestionar con tiempo su regreso a la

36. Iguíniz, "El Sagrario Metropolitano...”, op. cit., pp. 49-50. 
ciudad de México. El 2 de julio del mismo año el arquitecto insistió sobre esta cuestión, comentando que al aproximarse el vencimiento de su contrato y sin tener noticias al respecto, necesitaba regresar a México. La urgencia por resolver este tema se debía a la precaria situación económica que Mariano Mendoza tenía en Guadalajara y a la posibilidad de adquirir nuevos contratos de la Academia de San Carlos, el ayuntamiento y otras comunidades religiosas en la capital. ${ }^{37}$ Días más tarde, el cabildo eclesiástico confirmó la permanencia del arquitecto para proseguir con las obras de las torres y el sagrario, autorizando a Diego de Aranda la realización del nuevo contrato. La necesidad de continuar con los trabajos en la catedral y el sagrario obligó al cabildo a tomar esta decisión, a pesar de no haber fondos destinados a las obras, pero sí seguridad para ir proporcionando los mismos. De esa forma, se especificó que si los fondos con que se contaba no eran suficientes para las dos obras, se diera prioridad a la del sagrario, al ser de mayor necesidad y así cumplir con la voluntad del obispo Alcalde y Barriga. El 3 de agosto se volvió a comisionar a Diego Aranda, asignándole plena facultad para ambas obras. ${ }^{38}$ Las condiciones del contrato del arquitecto se indicaron el I2 de agosto de I830. En él se acordó que continuaría con el mismo sueldo de 2000 pesos anuales hasta concluir la obra que estaba pendiente en la catedral. Una vez finalizada ésta, Mendoza pasaría a recibir 3 ooo pesos anuales para realizar de forma simultánea las obras de las torres y el sagrario, de los que sólo percibiría 2400 pesos, pues con la diferencia amortizaría los anticipos recibidos. El académico había solicitado un suplemento económico en varias ocasiones, ascendiendo uno de ellos a I iı 6 pesos y 5 reales y medio, y otro a I ooo pesos. Así, los 600 pesos restantes del sueldo estipulado se reservaron para cubrir la deuda. ${ }^{39}$

A pesar de los buenos propósitos que el cabildo eclesiástico depositó en la necesaria continuación de las obras, los escasos recursos económicos y otra serie de cuestiones políticas y religiosas obligaron a que se volvieran a suspender los trabajos de construcción. Este motivo desencadenó un conflicto entre el cabildo y el académico Mariano Mendoza, que exigió una indemnización

37. Mariano Mendoza alegó que no podía mantener a una familia compuesta por I6 personas con un sueldo de 2000 pesos anuales. AHCEG, "Expediente formado con motivo de las obras de el sagrario y torres de esta catedral y el nuevo ajuste de su director don Mariano Mendoza", Sección Secretaría, Serie Hacienda, I830, caja 25, exp. 9, s.f.

38. Idem.

39. AHCEG, "Expediente sobre la obra de el sagrario y torres de la iglesia", Sección Secretaría, Serie Hacienda, I833, caja 28, exp. 25, s.f. 


\section{ENRIQUE CAMACHO CÁRDENAS}

acorde con los daños profesionales y económicos provocados por la paralización de las obras. El cabildo eclesiástico, para justificar su decisión, se remitió al contenido del contrato que había firmado con el director de la obra, subrayando el cuarto punto:

Si por algún motivo prudente a juicio del venerable cabildo tuviese a bien desistir de las obras antes de comenzarse o después de emprendidas en términos que le sea al facultativo Mendoza retirarse en solicitud de otro destino por no ocuparlo ya la Iglesia en el primer caso se le condonará la cantidad de quinientos pesos y en el segundo el resto de su deuda no pasando de mil pesos en consideración de haber prescindido ahora de la plaza que pudo obtener en este Estado o la que estaba en disposición de ir a servir a México concluida la obra actual.

Así, el I5 de marzo de I833 se decidió suspender el sueldo del académico, proporcionándole una compensación de 500 pesos por los daños causados. ${ }^{40} \mathrm{La}$ decisión no complació al arquitecto, que vio en la resolución del problema otros factores de diversa índole. Mendoza afirmó su conocimiento sobre la existencia de fondos para las obras, así como el interés que, al parecer, el canónigo Diego de Aranda tenía hacia la obra. Según el académico, Aranda quería apoderarse de la dirección de la obra sin tener conocimientos científicos para llevarla a cabo. De hecho puntualizó que, por orden del comisionado, estaba copiando los planos de la obra un aprendiz que Aranda tenía a su cargo.

El 22 de abril, Mariano Mendoza pidió la indemnización al cabildo eclesiástico por incumplimiento de contrato y perjuicios ocasionados con motivo de la suspensión de las obras. El arquitecto manifestó su queja sobre esta cuestión, ya que habían pasado ocho meses desde la finalización de las obras de cerramiento en el recinto y aún no se habían reiniciado las de las torres y el sagrario. Además añadió que seguía percibiendo un sueldo de 2000 pesos anuales y no el acordado en el nuevo contrato. Por eso solicitó "al menos" Io ooo pesos para pagar a la Iglesia, antes de su regreso a México, los anticipos que le había concedido, cubrir los gastos de su viaje y nuevo establecimiento en México, así como para subsistir durante un año aproximadamente hasta encontrar un nuevo trabajo. ${ }^{4 \mathrm{I}}$

40. Idem.

4I. Según Mendoza, a causa del nuevo contrato para realizar los trabajos de las torres y el sagrario, prescindió del puesto de director de Arquitectura de la Academia de San Carlos, de 
El i de junio se contestó a todas las reclamaciones que el arquitecto había formulado. Se le hizo ver que sin hacer ningún trabajo en la catedral se le siguió pagando sueldo durante esos meses, siendo la cantidad de 233 pesos lo que la Iglesia novogalaica le podría deber, en proporción al sueldo acordado de 2400 pesos anuales. Por otro lado se afirmó que la indemnización acordada para este caso fue de 500 pesos, siendo esta cifra lo único que se le debía al arquitecto. Además, se puntualizó que Diego de Aranda, como comisionado de la obra, gozaba del derecho de ordenar que se copiaran los planos. También se insinuó en esta contestación que el arquitecto, mientras disfrutaba de su puesto de director de la obra, aceptó un empleo por parte del gobierno civil que iba en contra de lo establecido en el contrato. A pesar de todo, se propuso que la indemnización fuera superior a 500 pesos, teniendo en cuenta la numerosa familia del arquitecto, la labor desarrollada en Guadalajara para la Iglesia durante más de tres años, así como la distancia a la que se encontraba de México y sin trabajo. Tampoco con esta solución quedó conforme Mendoza; solicitó una indemnización de al menos 6000 pesos y pidió que este asunto se resolviera en los juzgados consulares. Para evitarlo se celebró un acto de conciliación ante el alcalde constitucional, Onofre Reyes, quien obligó al cabildo eclesiástico a seguir pagando el sueldo de director de obra de la catedral a Mariano Mendoza. ${ }^{42}$ El comisionado Diego de Aranda manifestó en nombre del cabildo su disconformidad con dicha resolución, solicitando que se formalizara el juicio para resolver este problema. Pero finalmente el cabildo eclesiástico accedió a proporcionarle 4000 pesos, por lo que el arquitecto se comprometió a renunciar al contrato que tenía con la Iglesia. ${ }^{43}$

Las obras se reanudaron en I 835 gracias al empeño de Diego Aranda, quien encomendó la continuación de los trabajos de construcción al joven Manuel Gómez Ibarra, discípulo de José Gutiérrez. ${ }^{44}$ Oriundo de Guadalajara, estudió en el Seminario Conciliar y en el Instituto de Estudios Superiores, en el que obtuvo el título de arquitecto. Con posterioridad viajó a Europa para estudiar

la misma forma que rechazó el puesto de arquitecto de la Catedral de México y otros ofrecidos por diversas órdenes religiosas. Además, no aceptó la propuesta que el gobierno del estado de Jalisco le hizo como director de "Caminos" por dedicarse a las obras de la catedral. Idem.

42. En dicho documento, el alcalde se dirige al arquitecto en calidad de coronel. Idem.

43. De los 4000 pesos se le descontaron los 2 i 6 pesos y 5 reales y medio pertenecientes a la deuda que tenía con dicho cabildo eclesiástico. Idem.

44. Iguíniz, "El Sagrario Metropolitano...", op. cit., p. 50. 
las principales obras clásicas y renacentistas. ${ }^{45} \mathrm{Al}$ mismo tiempo que se dedicaba a los trabajos de construcción del sagrario, Gómez Ibarra fue el encargado de finalizar el edificio del hospicio Cabañas a partir de I836, prolongando su participación en la obra a lo largo de nueve años. ${ }^{46}$ En la obra del sagrario, el arquitecto tapatío siguió el proyecto de su maestro, aunque introdujo modificaciones en algunas partes puntuales del edificio y en la cúpula en su totalidad. Si bien la dedicación del templo tuvo lugar el I3 de septiembre de I839, los trabajos de ornamentación continuaron durante los años sucesivos hasta su conclusión en I843 (fig. 4).

La débil cimentación del templo o las modificaciones incorporadas en el diseño de la cúpula por Gómez Ibarra hicieron que el inmueble sufriera los primeros daños materiales pocos años después. Así, el I3 de octubre de I846 el arquitecto comunicó al nuevo obispo Diego Aranda los graves problemas de filtraciones que existían en la cúpula, los cuales provocaron la caída de un trozo de ornamentación. En ese momento Gómez Ibarra expresó que el arquitecto José Ramón Cuevas, al ver el estado en que se encontraba el inmueble, había comentado que no encontraba peligro inmediato en la fábrica. Pero el temblor de tierra que sufrió la ciudad el 2 de octubre de I847 incrementó de forma notable dicho problema. La cúpula quedó rajada y por ese motivo el cabildo eclesiástico pidió al arquitecto José Ramón Cuevas el reconocimiento de la misma, así como el de la catedral. El arquitecto recomendó el derribo inmediato de la cúpula, ya que amenazaba con caer sobre la fábrica de la catedral. Al final se procedió a la recomposición de la fábrica con algunas obras de refuerzo que lograron evitar el anunciado derrumbe. ${ }^{47}$

El i I de febrero de 1875 se produjo en Guadalajara el primero de una serie de temblores, ocasionando nuevas alteraciones en el inmueble. En esta ocasión se resintieron las bóvedas del crucero y además se desplomó una de las columnas exteriores de la cúpula, quedando ésta muy deteriorada. Tras reconocer el edificio varios ingenieros y arquitectos, se decidió derribar en su totalidad la cúpula y edificar una nueva, aunque al final sólo se efectuó una reforma que volvió a impedir la destrucción. Los trabajos de reforma los realizó el mismo arquitecto Gómez Ibarra. El costo total de la reparación de la cúpula y las bóve-

45. Huízar Zuno, "El neoclásico", op. cit., p. 377.

46. Rosas et al., Hospicio Cabañas, op. cit., p. 99.

47. Iguíniz, "El Sagrario Metropolitano...", op. cit., pp. 50-5I; Archivo Histórico de la Arquidiócesis de Guadalajara (en adelante AHAG), Sección Gobierno, Serie Cabildo, caja 4. 
4. Portada lateral del Sagrario Metropolitano de Guadalajara. Foto: Enrique Camacho Cárdenas, 20 Io.

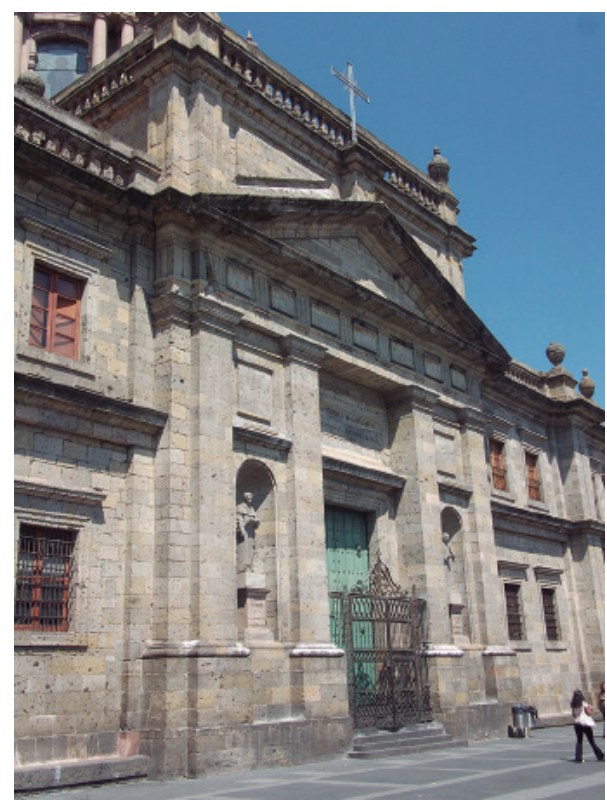

das fue de 8000 pesos. Por este motivo y hasta que finalizaron las reformas en I878, el culto del sagrario se trasladó al templo de la universidad. ${ }^{48}$ Con anterioridad a éstas se llevaron a cabo otras reformas en el inmueble, pues el i I de marzo de 1864 el cabildo acordó que se realizaran las reparaciones indispensables en el edificio a juicio de Gómez Ibarra. ${ }^{49}$ Aun así, la cúpula fue el elemento arquitectónico que más sufrió los temblores de tierra que asolaron la ciudad, ya que en I899 otro sismo la volvió a deteriorar, siendo el autor de la actual el ingeniero Antonio Arróniz (fig. 5).50

Si bien el obispo Juan Cruz Ruiz de Cabañas fue una figura clave para que un maestro académico se estableciera en la ciudad con el fin de cumplir los objetivos y subsanar las carencias que se han comentado, resultó imprescindible el apoyo de otras personalidades. El deseo de Carlos IV de que se realizaran las trazas del sagrario de acuerdo con los postulados de la Academia, al

48. Iguíniz, "El Sagrario Metropolitano...”, op. cit., pp. 54-56.

49. No se especifican los problemas que había en el edificio en esa fecha. AHCEG, Libro de actas de reuniones de "Pelicano", I773-1880, f. I49r.

5o. Iguíniz, "El Sagrario Metropolitano...", op. cit., p. 57. 


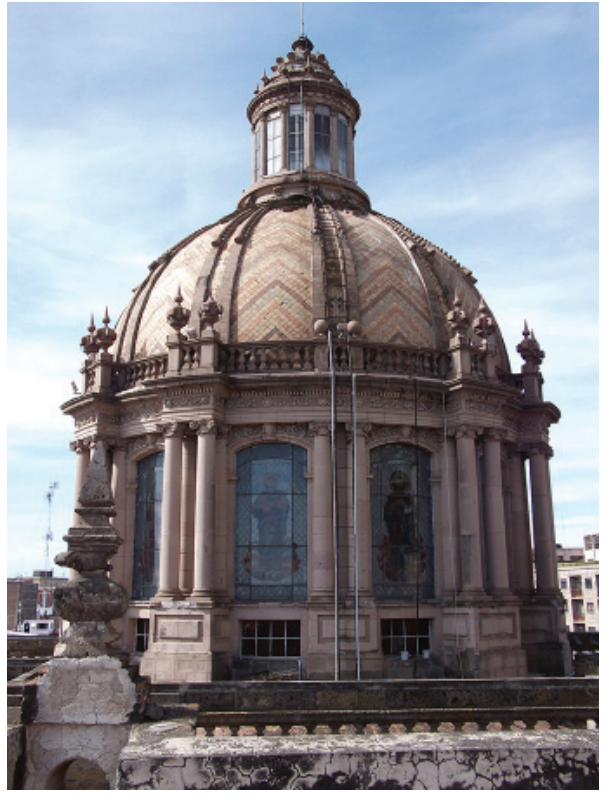

5. Cúpula actual del Sagrario Metropolitano de Guadalajara. Foto: Enrique Camacho Cárdenas, 2010.

igual que Abascal, presidente de la Audiencia de Guadalajara, junto a la propuesta de Tolsá para que José Gutiérrez llevara a cabo su proyecto del hospicio y la recomendación de González Velázquez de ser el autor de las trazas el que estuviera al mando de la dirección de la obra, hicieron posible que el arquitecto malagueño fuera el protagonista de la introducción del neoclásico en Guadalajara. El templo del sagrario, edificado prácticamente en ıo años, tuvo tres momentos o intentos para su construcción, si bien la fábrica se realizó casi en su totalidad en el momento en que Manuel Gómez Ibarra se hizo con la dirección de la obra. Llevar a cabo las principales labores de edificación en el periodo comprendido entre I808 y I 843 hizo que el proyecto original se respetara sin grandes modificaciones, con excepción de la cúpula, lo que dotó al inmueble de una clara unidad arquitectónica.5 ${ }^{\text {I }}$

5I. Para la descripción arquitectónica del edificio véase la segunda parte de la mencionada obra de Iguíniz, "El Sagrario Metropolitano...", op. cit., pp. 58-74. 


\section{APÉNDICE DOCUMENTAL}

\section{Documento $\mathbf{I}^{52}$}

Mayo I785.

Expediente formado con motivo de la donación del ilustrísimo señor Alcalde para la construcción del Sagrario.

[Guadalajara, I3 de mayo de I785]

[Margen] Donación del Ilustrísimo señor Alcalde para la construcción del Sagrario, 1785 .

En la ciudad de Guadalajara a trece de mayo del mil setecientos ochenta y cinco años. Ante mí el escribano de su Majestad y testigos, el Ilustrísimo y Rmo. señor Maestro Don fr. Antonio de Alcalde del Sagrado Orden de Predicadores, obispo de esta Diócesis, del Consejo de su Majestad, santísima mi señor. Dijo, que advirtiendo la necesidad que hay en esta Santa Iglesia Catedral de capilla Parroquial para el Sagrario, de baptisterio y demás oficinas necesarias por haberse demolido las que serían a este efecto por ruinosas, indecentes, viejas y fabricadas de adobe: Deseando su señoría Ilustrísima proveer tan noble y grave necesidad, fabricando todas estas piezas de materia y arquitectura correspondiente a la Santa Iglesia Catedral, a su Majestad y decoro, lo participó su venerable Deán y Cabildo para que de común acuerdo se ocurriese por la licencia a su Majestad, practicándose previamente las diligencias después por las leyes y cédulas reales, expresando que la referida fábrica se haría sin gravamen de los caudales de la Santa Iglesia, ni de la Real Hacienda, sino a expensas de un bienhechor, cuyo nombre se calló y declara serlo ahora su señoría Ilustrísima y considerando ser suficientes los fondos de su renta que se halla, y a mayor abundamiento adquirirá en el tiempo que sobreviva, y que no puede dudarse la licencia de su Majestad para igual obra indispensable y necesaria y que sin notable perjuicio no puede diferirse: ha resuelto su señoría Ilustrísima que sin pérdida de tiempo se comience supuesto el ocurso hecho; a cuyo efecto irá contribuyendo formándose primero un Mapa o Diseño de la fábrica a satisfacción del venerable Deán y Cabildo, y de la suya, todo lo necesario para ella mientras viva; y para que no falten los auxilios suficientes a verificar su perfecta conclusión, aunque estima su señoría Ilustrísima ser bastantes los que tiene devengados correspondientes a su Cuarta Episcopal, y

52. AHCEg, Sección Hacienda, Serie Culto, caja I, exp. I9, s.f. 
mucho más los que devengare, y correspondan hasta el día de su fallecimiento. Por el presente instrumento hace cesión, gracia y donación de unos y otros, cierto y sabedor de sus derechos y acciones y de las que en el caso le pertenecen a favor de la nominada obra del Sagrario, Bautisterio y oficinas bajo las calidades siguientes: Primera que por esta cesión, gracia y donación no se embaraza, ni priva su señoría Ilustrísima mientras viva de expender, distribuir, y gastar a su voluntad cuanto sea conveniente a su familia, decencia de su estado y dignidad, en socorrer la necesidad particular de los pobres las públicas que se ofrezcan de hambre, enfermedad, ni en todos aquellos socorros que sean propios de la piedad y de su ministerio pastoral, pues queda libre para hacerlos y distribuir de sus rentas cuanto estime oportuno para otros fines, en la propia forma que lo ha estado antes de esta donación. Segunda, que cuanto se hallare devengado y ganado perteneciente a su Cuarta Episcopal hasta el día de su muerte, a más de lo que hubiere expedido y contribuido para esta fábrica, se entiende cedido y donado a beneficio de ella sin embargo de que se halle concluida la obra material, o de que para finalizarse se necesite menos cantidad que la que le pertenezca, pues quiere que el sobrante se convierta y aplique todo a su adorno y culto del señor sacramentado. Tercera, que aunque dicha fábrica ha de dirigirse y trabajarse por alarifes y maestros peritos, en la facultad para que se construya con el arreglo que pide el arte, con la hermosura y perfección necesaria a su magnificencia, y con la firmeza que asegure su duración, quiere para el logro de tan justos fines, y con autor de ella, que su dirección camine bajo su aprobación, y el nombramiento de intendente de ella de arquitecto, sobrestante o mayordomo, ser propio y probativo de su señoría Ilustrísima mientras viva; y que la cuenta de gastos se le presente siempre que la pida por el intendente. Y por fallecimiento de su señoría Ilustrísima la dirección, nombramientos sobre dichos, glosa, y revisión de cuentas, recaigan y pertenezcan a las tres primeras dignidades de esta Santa Iglesia, es a saber los señores Deán, Arcediano, y Chantre, y por defecto de alguno o algunos de estos entren la dignidad o dignidades que por su orden siguen, acompanándoles a los tres en la dirección y cargos referidos el mayordomo de fábrica Don Juan Alfonso Sánchez Leñero, para que todos cuatro de común acuerdo entiendan en la obra, ministren los gastos, tomen cuentas, reciban el dinero donado conservándolo en arca separada, y lo distribuyan a beneficio del Sagrario en lo que su arreglado árbitro juzgue más oportuno. Y bajo de esa disposición, y calidades otorga su señoría Ilustrísima este instrumento de cesión, gracia y donación intervivos, pura, mera, perfecta e irrevocable con el principal y único objeto de expender en tan 
piadosos y santos fines, y a beneficio de su propia Iglesia, en cumplimiento de la obligación de su pastoral ministerio, las rentas eclesiásticas que la providencia divina le ha confiado para dispensador de ellas. Y para la mayor firmeza, perpetuidad y valor de esta donación, muy distinta y ajena, aun de la sombra de la más leve sospecha de perjuicio y fraude de los derechos de su Iglesia, la jura por tal en debida forma. Y para que se entienda hecha real y efectiva, tiene puesto en la clavería todo lo derogado, y los derechos que de presente le pertenecen por su Cuarta Episcopal para su efecto y cumplimiento, pues los gastos que le sean precisos, o conveniente para otros fines, conforme a la reserva hecha arriba los irá erogando de lo que desde la fecha de este instrumento fuere adquiriendo con su Cuarta Episcopal; sin valerse de lo adquirido hasta ahora, ni tomar de ello más cantidad o cantidades que las que acaso se necesiten para cubrir sus gastos y contribuciones piadosas, y no alcancen sus rentas futuras, que así lo declara y protesta.

[Margen] Aceptación

Y habiendo leído yo el presente escribano este instrumento de donación al venerable señor Deán y Cabildo de esta Santa Iglesia, entendido de él de su tenor, calidades y cláusulas, dijeron parecerles todo arreglado a derecho sin hallar en él cláusula alguna que perjudique los derechos de la Santa Iglesia, ni cosa alguna que se oponga a su valor y firmeza, y que como tal no solo lo aceptaran y aceptaron, sino que daban y dieron muchas y muy debidas gracias a su señoría Ilustrísima a su nombre, y en el de la Santa Iglesia, como que toda la donación redunda en utilidad y beneficio de ella por el religioso celo y generosa piedad que ha conducido el espíritu y corazón de su señoría Ilustrísima para obra tan grande y que toda se termina al culto y servicio de Dios y señor sacramentado: En cuyo testimonio así lo otorgaron y firmaron en este registro siendo testigos el Venerable D. Anacleto Rafael Escoto, Presbítero familiar de su señoría Ilustrísima, el Venerable D. Manuel Cavallero, también Presbítero secretario de Cabildo de esta dicha Santa Iglesia Catedral, y D. José Narciso Pérez, Notario público de la curia eclesiástica de este obispado, presentes y vecinos. Sr. Antonio obispo de Guadalajara, Nicolás López Portillo, Doctor Vicente Antonio Flores Alatorre, Doctor José Antonio Martínez Venavides, Doctor Manuel Gutiérrez, Licenciado Pedro Díaz Escandón, Juan José Moreno, Manuel Domingo de la Fuente, Pedro Miguel Quintano, José Álvarez de Lava, Juan Ignacio de Moya, José de Fintos, Nicolás Colado Posada y Platas, Doctor Francisco Morales, Ante mí Blas de Silva, Escribano Real. Sacado de su registro día del otorgamiento en estas seis fojas útiles, la primera del sello 
segundo, y las demás del común. En testimonio de verdad, Blas de Silva, Escribano Real.

En testimonio de verdad.

Fernando de Cuéllar Morroy. Secretario de Cabildo.

\section{Documento $2^{53}$}

[Expediente] Año de I804. El señor Presidente de Guadalajara sobre que la Real Academia de San Carlos forme el Plano para la obra de la Parroquia de aquella Santa Iglesia y se envíe Facultativo capaz de ejecutarla.

$$
\text { [ff. 2r-3v] }
$$

[Margen] México 29 de septiembre de I804. Pase a informe de la Real Academia de San Carlos.

[Guadalajara, 4 de septiembre de I804]

\section{Excelentísimo Señor.}

En real cédula de 3 de enero de este año me manda S.M. proceder de luego a luego a la construcción de la Parroquia sagrario de esta santa Iglesia Catedral arreglada a plano que ejecute esa Real Academia de San Carlos a quien le debo pedir: En consecuencia dirijo a V.E. el del terreno sobre que se ha de fabricar dicho edificio con las advertencias que me han parecido conducentes al mejor acierto, a fin de que teniendo V.E. la bondad de pasarlo a dicho cuerpo ejecute el dibujo con la correspondiente elevación, y cortes y perfiles que convengan para la mejor inteligencia de la obra; la que espero sea digna de la ilustración de dicha Academia, de la época en que vivimos, y de los deseos de S.M. de que cuantas se ejecuten en su tiempo correspondan a la más exacta arquitectura; en inteligencia de que el costo que tenga este trabajo, será pagado por mí, en el momento que se me avise.

Como en esta ciudad se carece absolutamente de facultativo capaz de ejecutar la obra según el plano, contemplo indispensable que venga de ahí un profesor aprobado por la Academia, así para el mayor acierto de la que se va a

53. AGN, Instituciones Coloniales, Indiferente Virreinal, caja 3026, exp. 002. 
hacer, como para que, encargándose de algunos particulares, pueda dar idea del buen gusto de la facultad a los maestros de esta ciudad; en cuya atención he de merecer a V.E. que el mismo cuerpo elija uno de las circunstancias expresadas, avisándome del estipendio anual con que se convenga a venir, por determinar lo conveniente.

Dios guarde a V.E. muchos años. Guadalajara 4 de septiembre de I804.

Excelentísimo señor.

Joseph Fernando Abascal

[Margen inferior izquierdo] Excelentísimo Señor Virrey D. José de Iturrigaray.

[ff. $4 \mathrm{r}-5 \mathrm{v}]$

[México, 22 de enero de I805]

En cumplimiento de la orden de V.S. de 8 de octubre del año anterior en que se sirve mandar forme los planos para la fábrica de la Iglesia del Sagrario de la Catedral de Guadalajara, remito a V.S. la representación y Plano del terreno que para este fin me acompańó, y los nuevamente ejecutados con arreglo a dicho plano, los que constan de planta, fachada, costado y corte interior, inventados y delineados por el Arquitecto Académico de mérito de esta Real Academia de San Carlos don José Gutiérrez, siendo los indispensables para la precisa inteligencia de la mencionada obra; no habiéndolos yo ejecutado respecto a la cortedad de mi vista, que es notoria. Estos están bien arreglados con la robustez, comodidad, hermosura y decoro que requieren y el asunto exige; en fin, dignos de la ilustración de la Real Academia, de la época en que vivimos y de los deseos de S.M. de que cuantas obras se ejecuten, estén sujetas a Planos, como los mencionados; cumpliendo de este modo con sus regios deseos, pues ellos corresponden a la más exacta Arquitectura. Dichos Planos soy de dictamen, que con equidad valen trescientos pesos. En cuanto a que informe a V.S. del Facultativo capaz de ejecutar la obra según los Planos, debo decir, que no hay otro mejor que el mencionado Gutiérrez; pues éste es aprobado por esta Real Academia en el ramo de Arquitectura, perfectamente instruido en ella, ha ejecutado los Planos, y podrá verificar mejor sus ideas, y darles toda la majestad que requieren: este sujeto es honrado, de buena conducta, y tiene las circunstancias que menciona dicha representación; y se conviene a dirigir la mencionada obra por dos mil pesos anuales de sueldo fijo; ministrándole en caso de su aprobación, ochocientos pesos adelantados para el costo de 
su viaje, los que pagará con un descuento paulatino, contándosele este sueldo desde el día en que se ponga en camino, recogiendo para este fin la correspondiente certificación. Y en atención a los méritos que tiene contraídos de veinte años de estudio y servicios en esta Real Academia y al Empleo que goza de sustituto de Arquitectura, por lo cual le están consignados setecientos pesos anuales, suplica a V.S., si lo tiene a bien, se sirva elevarlo a la superioridad, a fin de que se le conceda la retención de su Empleo sin el goce de los setecientos pesos mencionados, y que se le cuente todo el tiempo que estuviese fuera de la Real Academia como en actual servicio, con todas las opciones y ascensos que en lo sucesivo le correspondan por su línea; y concluida la obra, se le ha de restituir a su actual Empleo, librándose a este efecto las órdenes oportunas a esta Real Academia para su inteligencia y cumplimiento. Dios guarde a V.S. muchos ańos. México I8 de enero de I805. Antonio Velázquez. Señor Presidente de la Real Academia de San Carlos, Marqués de San Román. Es copia, México 22 de enero de I805.

$$
\text { [ff. 6r-7v] }
$$

[México, 23 de enero de 1805.$]$

\section{Excelentísimo Señor}

Devuelvo a V.E. la representación del Señor Presidente de la Real Audiencia de Guadalajara con el Diseño que incluía, y acompaño en un cañón de hoja de lata los Planos, formados para la construcción de la nueva Parroquia del Sagrario de aquella Santa Iglesia Catedral por el Académico de mérito Don José Gutiérrez, a fin que, en su vista y de la copia certificada del informe, que hizo sobre todo el Director de Arquitectura Don Antonio Velázquez se sirva V.E. resolver lo que juzgue conveniente; asegurando que solo el mismo Gutiérrez cuya habilidad y juiciosa conducta es bien conocida, podrá desempeñar completamente la indicada obra.

Dios guarde a V.E. muchos años. México 23 de enero de i805.

Excelentísimo Señor

Marqués de San Román

[Margen inferior izquierdo] Excelentísimo Señor Virrey Viceprotector Don José Iturrigaray. 
[ff. 8r-v]

[Guadalajara, 3i de enero de I805]

El Excelentísimo Señor don José Fernando Abascal, Presidente que fue de esa Real Audiencia en oficio de 4 de septiembre último manifestó al Excelentísimo Señor Virrey que por Real Cédula de 3 de enero anterior se le prevenía procediere desde luego a la construcción de la Parroquia Sagrario de esa Santa Iglesia Catedral, arreglado al Plano que ejecutase la Real Academia de San Carlos, y que en esta virtud acompañaba el del terreno en que había de fabricarse a fin de que sirviéndose Su Excelencia pasarlo a dicho cuerpo formara el dibujo correspondiente para la mejor inteligencia de la obra; bajo el concepto de que el costo de ese trabajo sería satisfecho inmediatamente; y concluía con que la propia Real Academia eligiere un Facultativo que fuese capaz de ejecutarla, así como para encargarse de otros particulares aviándole el honorario con que se convendría a ir este individuo.

En su consecuencia tuvo a bien el mismo Excelentísimo Señor Virrey pasar todo a informe de la citada Academia; y habiéndolo evaluado según se advierte de las dos copias certificadas que son adjuntas; las remito a V.S. como Delegado de Su Excelencia, e igualmente en un cañón de hoja de lata los Planos firmados para la indicada obra, a fin de que con presencia de todo determine V.S. lo que tenga por conveniente.

D. Enero 3i/805.

[Margen inferior izquierdo] Señores Regente y Oidores de la Real Audiencia de Guadalajara.

\section{Documento $3^{54}$}

[Documento incluido en el expediente] Año i805. Sobre el nombramiento de Maestro de Arquitectura para las obras que ocurran a la Fábrica de esta Santa Iglesia.

[Guadalajara, 7 de enero de I805.]

[Carta del obispo de Guadalajara al cabildo de la catedral en la que se informa sobre el conocimiento de un maestro de arquitectura y dibujo que se pue-

54. AHCEg, Sección Secretaria, Serie Hacienda, caja I3, exp. 26, s.f. 
de establecer en la ciudad y a su vez se nombre arquitecto de la fábrica de la catedral.]

\section{Ilustrísimo Señor}

Muy señor mío. Con el objeto de que se establezca en esta Ciudad un Maestro hábil que pueda dar lecciones públicas de Arquitectura y Dibujo, y con el de que éste sea un hombre de recomendables circunstancias he procurado saber si en la Ciudad de México hay alguno a propósito. Lo hay efectivamente y nada dudo que proporcionándole una subsistencia honrosa acepte su traslación a esta Capital. Por mi parte estoy resuelto a contribuirle un mil pesos anuales; más como podrá serle de mucho aliciente el que esta Santa Iglesia lo nombre su Arquitecto y Maestro de las obras que ocurran a la Fábrica. Lo hago presente a V.S.Y. de cuyo amor y celo por el bien público tengo tantas pruebas para que si es de su agrado el promoverlo en este punto me diga si está en disposición de conferir el expresado nombramiento y de consignar al indicado Maestro de los fondos de Fábrica alguna pensión anual.

Dios que a V.S.Y. Guadalajara, enero 7 de 1805 .

Juan Cruz Obispo de Guadalajara

[Margen inferior izquierdo] Ilustrísimo Señor Presidente y Cabildo de esta Santa Iglesia Catedral. \$s

* Artículo recibido el 2 de junio de 20 I I; aceptado el I6 de noviembre de 20 I I. 